\title{
Multilayers Polyethylene Film for Crop Protection in Harsh Climatic Conditions
}

\author{
A. Dehbi, ${ }^{1}$ B. Youssef, ${ }^{2}$ C. Chappey, ${ }^{2}$ A.-H. I. Mourad, ${ }^{3}$ P. Picuno, ${ }^{4}$ and D. Statuto ${ }^{4}$ \\ ${ }^{1}$ Laboratoire de Génie Physique, Université d'Ibn Khaldoun, BP 78, 14000 Tiaret, Algeria \\ ${ }^{2}$ Normandie University, INSA Rouen, UNIVROUEN, CNRS, PBS, 76000 Rouen, France \\ ${ }^{3}$ Mechanical Engineering Department, Faculty of Engineering, United Arab Emirates University, P.O. Box 15551, Al-Ain, UAE \\ ${ }^{4}$ SAFE School, University of Basilicata, Via dell'Ateneo Lucano no. 10, 85100 Potenza, Italy \\ Correspondence should be addressed to P. Picuno; pietro.picuno@unibas.it
}

Received 7 December 2016; Accepted 10 January 2017; Published 30 January 2017

Academic Editor: Gianluca Cicala

Copyright (c) 2017 A. Dehbi et al. This is an open access article distributed under the Creative Commons Attribution License, which permits unrestricted use, distribution, and reproduction in any medium, provided the original work is properly cited.

In this work the performance and durability of a new generation of greenhouse covers, in which the cover is composed of five layers, are investigated. A sand wind ageing was performed under different exposure conditions. Surface morphology and chemical, physical, and thermal characteristics were investigated by using optical microscopy, FTIR, and tensile test techniques. In addition, the mechanical integrity of the five-layer film was assessed. The analysis indicated that the sand wind treatments have a significant influence only on the performance of the film. An attempt has been done to compare the properties of the five-layer film with the monolayer and trilayer films with or without air bubble under similar conditions. The results revealed that the five-layer film proved to be a promising greenhouse covering film.

\section{Introduction}

The growing use of plastics in agriculture results in increased yield, earlier or delayed harvest, less reliance on herbicides and pesticides, better protection of food products, and more efficient water conservation [1-3]. According to most recent estimation [4-6], the annual consumption in the world of plastic material in the agricultural sector is approximately 5 million tons (about $2 \%$ of the total plastic production), and it seems to be steadily growing.

The protection of crops from hail, wind, snow, or strong rainfall in horticulture, together with the realization of a confined space with controlled microclimatic conditions, is the most common case. Plastic films are widely diffused for covering greenhouses, low and medium tunnels, and soil mulching (Figure 1). In greenhouse, the plastic cover is used to maintain favourable conditions of temperature, solar radiation, gas composition $\left(\mathrm{O}_{2}, \mathrm{CO}_{2}\right.$, and $\left.\mathrm{N}_{2}\right)$, and humidity in order to allow optimal photosynthesis, respiration, and growth of the plants.

Low-density polyethylene (LDPE) is one of the plastic materials most widely used as greenhouse cover [7-12]. In spite of the low cost of these polymeric materials, the economic advantages of plasticulture can be seriously damaged by extreme climatic factors, which decrease the lifetime of the plastic cover [13-18]. Despite the continuous efforts made by plastic producers $[19,20]$, this important characteristic is actually limited from four to five seasons in Europe and in US and from two to three seasons in Saharan environment $[21,22]$. The specific working conditions, that is, climatic parameters (air temperature, solar radiation, humidity, temperature of the contacting metallic frame, etc.) as well as other local actions (e.g., mechanical constraints, sand wind, contact with agrochemicals and pesticides, etc.), could indeed considerably modify some important technical properties like mechanical strength, radiometric properties, and gas permeability of the exposed plastic films [23-25]. Moreover, these effects promote the degradation of the polymeric film in its environment, resulting in an important residual pollution $[18,26,27]$.

Various researchers were interested in the long-term behaviour of these plastic covers. Guenachi et al. [28, 29] studied the effect of a sand wind simulation on a LDPE monolayer film, keeping it for 4 hours at $40^{\circ} \mathrm{C}$. They showed 


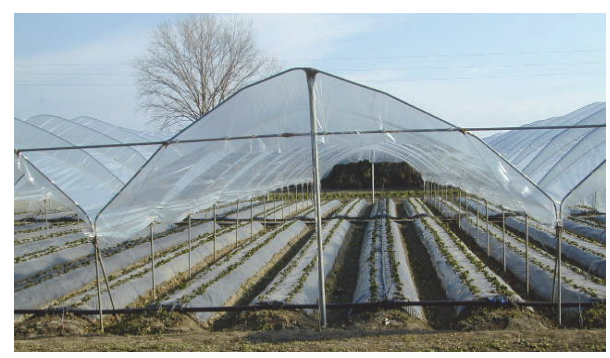

FIGURE 1: Plastic-covered tunnel with inside plastic soil mulching.

that this creates on the exposed surface a very thin layer of material inlaid with particles of sand. Dehbi et al. [21] reported that the durability of the material depends on its capacity to resist the erosion. Recently, Djakhdane et al. [30] have studied the impact of sand wind, temperature, and exposure time on trilayer polyethylene film. They have illustrated that the exposure to temperature and sand wind have severe degradable effects on the mechanical and radiometric characteristics of the film. The solar transmission of the film and its mechanical properties have reduced significantly due to exposure to sand wind and temperature.

The greenhouse covers are generally made up of monolayer films of LDPE having $200 \mu \mathrm{m}$ thickness. Due to the ageing and to the variation of their radiometric and mechanical properties, trilayer films [31-34] - typically with $220 \mu \mathrm{m}$ thickness made of LDPE, and poly(vinyl acetate) (PVA) with air bubbles entrapped in the middle layer - were developed (PROSYN-POLYAN). Due to the air bubble in the middle layer, this film is more efficient in maintaining the temperature in the greenhouse. However, trilayer films based on LDPE, produced by Agrofilm SA (Algeria) without air bubbles, showed better mechanical properties when compared to the monolayer LDPE film [35].

Recently, an innovative five-layer film for greenhouse was produced by Ginegar Plastic Products Ltd. From the literature survey, the present study could appear to be the first one about the five-layer LDPE film as a greenhouse covering. On the other side, no research was carried out concerning the gas permeation of multilayer greenhouse films. These points motivated the present work, in which the surface morphology and gases $\left(\mathrm{O}_{2}\right.$ and $\left.\mathrm{CO}_{2}\right)$ permeability behaviour of a five-layer film subjected to Saharan environment simulated conditions was considered. The film was exposed to sand wind for 8 hours at a temperature of $40^{\circ} \mathrm{C}$, as well as for 1000 hours at a temperature of $40^{\circ} \mathrm{C}$, and to UVA radiation conditions too. Since $\mathrm{O}_{2}$ and $\mathrm{CO}_{2}$ play a significant role for the growth of the plants, it is very important to have a systematic study on the permeability nature of these films. The properties of the five-layer films were then finally compared with those of the monolayer and trilayer films (with or without air bubbles) used as greenhouse covering under similar environmental conditions.

\section{Material and Methods}

2.1. Materials. The greenhouse covering film used for this study was supplied by Ginegar Plastic Product Ltd. with the trade name Sun Selector ${ }^{\mathrm{TM}} /$ SunTherm 4 . This film, obtained by using extrusion technique with a thickness of $200 \mu \mathrm{m}$, consists of five layers: two external polyethylene (PE) layers and a central poly(vinyl acetate) (PVAc) layer with two intermediate layers containing adhesives to ensure the cohesion between PE and PVAc. This intermediate layer containing adhesives consists of various additives such as anticondensation, anti-UV, antiparasite, antivirus, antidust, and antidrops.

In this study, the tests were conducted on the following films:

(a) Five-layer virgin film

(b) Five-layer film after artificial ageing for 1000 hours at $40^{\circ} \mathrm{C}$

(c) Five-layer film after artificial ageing for 1000 hours under UVA radiation at $40^{\circ} \mathrm{C}$

(d) Five-layer film after artificial sand wind simulation for 8 hours at $40^{\circ} \mathrm{C}$

2.2. Methods. A laboratory equipment/set-up, specifically designed and constructed for the artificial ageing, was described in our earlier studies $[34,35]$. This equipment was composed of a thermostatic tube, a sand wind chamber, and a control keyboard. From an air turbine, the flux was heated up to the targeted experimental temperature $\left(T=40^{\circ} \mathrm{C}\right)$, under a pressure of $100 \mathrm{kNm}^{-2}$, inside the thermostatic tube. This dry air was introduced in the sand wind chamber where natural sand particles were deposited. A Brownian movement of the sand particles resulted, striking randomly the polymer surface. A 30 Watts lamp was placed $20 \mathrm{~cm}$ away above the samples.

The surfaces of the films tested were examined before and after sand wind ageing by using a Leica DMLM microscope, Japan.

Fourier transform infrared (FTIR) spectroscopic analysis was recorded in total reflection on a Nicolet Avatar 360 instrument equipped with a germanium crystal. 128 scans were accumulated with a resolution of $4 \mathrm{~cm}^{-1}$ for each spectrum. IR spectra present absorbance from 3000 to $600 \mathrm{~cm}^{-1}$. The calculations were made for the various samples after standardization, according to a reference peak. The peak at $2920 \mathrm{~cm}^{-1}$ is chosen as reference because it remains identical for all the samples.

Tensile tests of films were carried out using a universal testing machine (Instron model 4301, France). The tests were performed using a $5 \mathrm{kN}$ load cell at a cross head speed of $2 \mathrm{~mm} / \mathrm{min}$. The tensile modulus $(E)$ was obtained from the tangent at the origin of the stress-elongation curve according to the AFNOR NF T54-102 [36]. The results obtained represent an average value calculated from five samples.

\section{Results and Discussion}

3.1. Optical Microscopy. Figure 2 shows the images obtained by the optical microscope for the trilayer and five-layer films, virgin (i.e., case (a), as in Section 2.1) and after exposition to sand wind for 8 hours at a temperature of $40^{\circ} \mathrm{C}$ (i.e., 

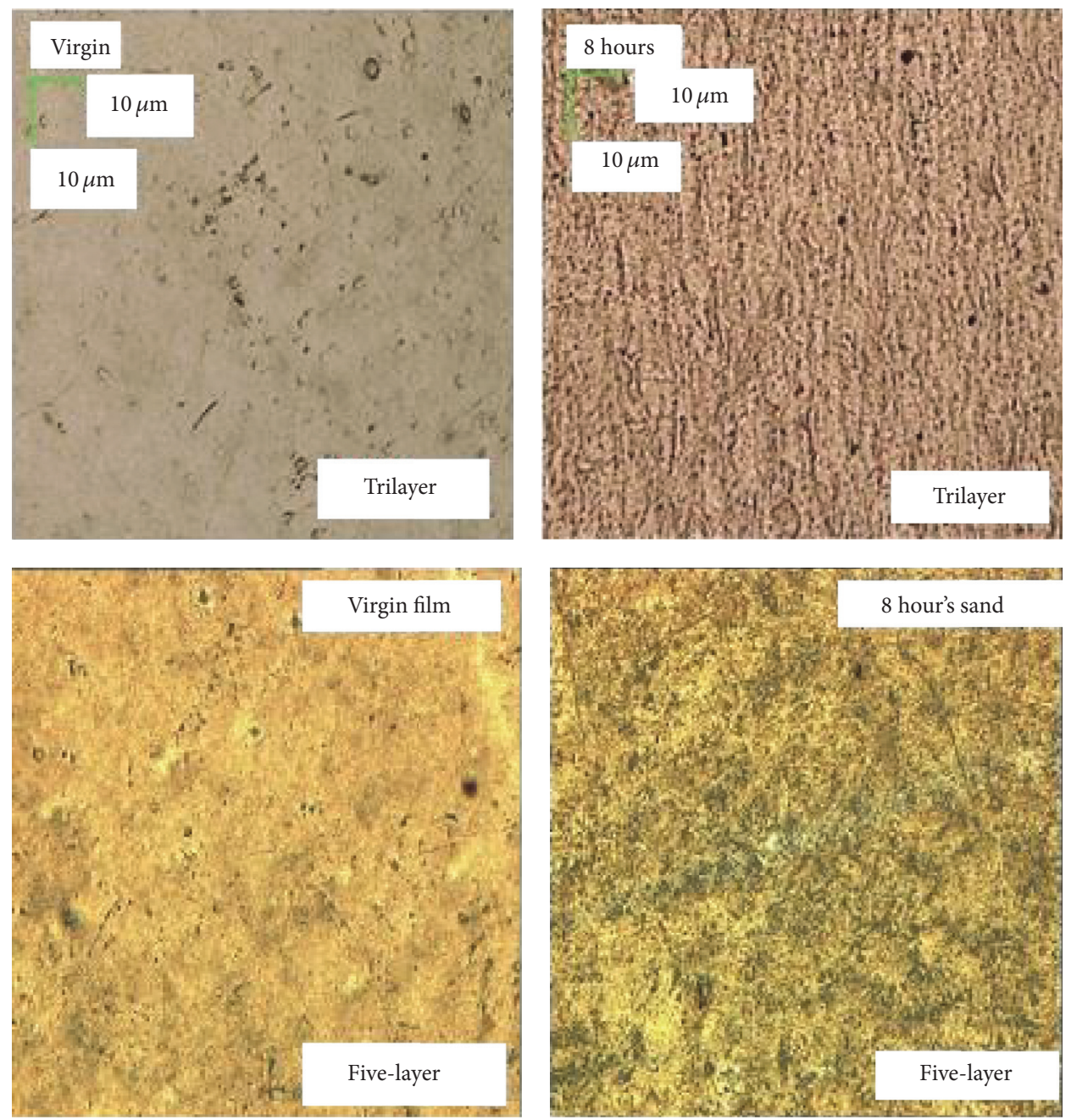

Figure 2: Microphotographs of the surface of the five-layer and trilayer films before (virgin) and after 8 hours of exposure to sand wind at $40^{\circ} \mathrm{C}$.

case (d), as in Section 2.1). The microphotographs obtained by using the incident light technique at the same lighting conditions show clearly the produced damage on the surface of the two films due to the impact of the sand particles. The effect of sand wind on the five-layer film surface is negligible compared to the trilayer film. The influence of abrasions may be recognized by cavities or the dark areas in the images. These abrasion mark sizes were increased with exposure time. While in the case of the a trilayer sample [16], after 8 hours of exposure to sand wind, the sand particles have been observed to cover completely the surface and the cavities - to the extent that the percentage of visible light transmission was almost zero - the damage effect was much less for the fivelayer film sample here tested. Because of the presence of air bubbles in the trilayer film, significant destruction occurs on the film surface. These results are in coherence with those reported in a similar research [30].

3.2. FTIR Analysis. In Figure 3 the FTIR spectra of the surface of the five-layer film are reported in correspondence of the different above-mentioned exposure conditions $(\mathrm{a}-\mathrm{d})$.
Figure 3(a) presents the initial film spectrum in which the characteristic bands of polyethylene are highlighted: $\mathrm{CH}_{2}$ stretching vibrations (2920 and $2850 \mathrm{~cm}^{-1}$ ), $\mathrm{CH}_{2}$ deformation vibrations $\left(1470 \mathrm{~cm}^{-1}\right)$, and $\mathrm{CH}_{2}$ skeleton vibrations $\left(720 \mathrm{~cm}^{-1}\right)$ [37, 38]. All these bands are present in the FTIR spectra of the aged samples (Figures 3(b), 3(c), and 3d) and grow with exposure time and become sharper.

Figure 3(b) presents the peaks of a film sample kept artificially aged at $40^{\circ} \mathrm{C}$ for $1000 \mathrm{hrs}$ exposure time. As ageing continued, new peaks appeared between 650 and $1750 \mathrm{~cm}^{-1}$ specifically at $1650 \mathrm{~cm}^{-1}, 1390 \mathrm{~cm}^{-1}$, and $1029 \mathrm{~cm}^{-1}$ that correspond to oxygenated groups and those at $1540 \mathrm{~cm}^{-1}$ and $1450 \mathrm{~cm}^{-1}$ which correspond to the absorption band of vibrations of $\mathrm{CH}_{2}-\mathrm{O}$ group [32] or $\mathrm{C}=\mathrm{C}$ double bonds. The spectra indicate that the intensity of the peaks increases as a function of time. A peak at $1740 \mathrm{~cm}^{-1}$, which corresponds to the formation of ester groups [39], is observed in Figure $3(\mathrm{~b})\left(40^{\circ} \mathrm{C}+1000 \mathrm{hrs}\right)$ and Figure $3(\mathrm{~d})\left(40^{\circ} \mathrm{C}+\right.$ $8 \mathrm{hrs}$ sand wind).

Figure 3(c) shows the FTIR spectra for the samples artificially exposed to UVA and $40^{\circ} \mathrm{C}$ temperature for $1000 \mathrm{hrs}$. It 


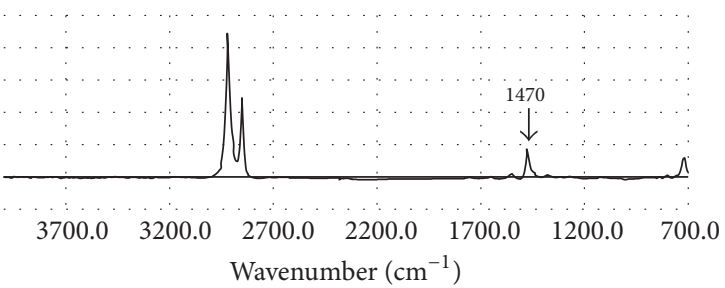

(a)

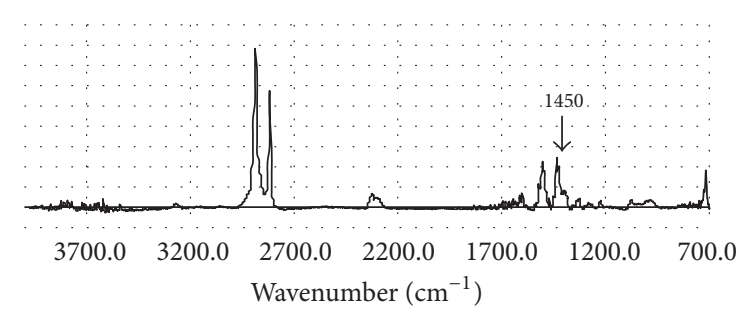

(c)

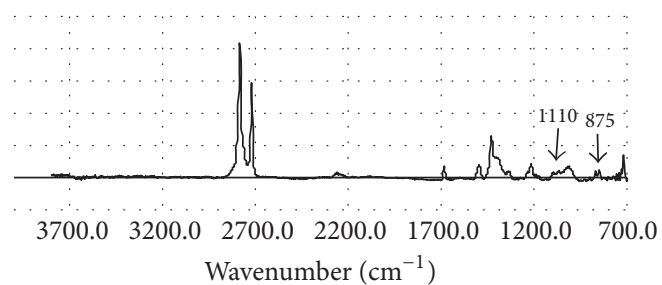

(d)

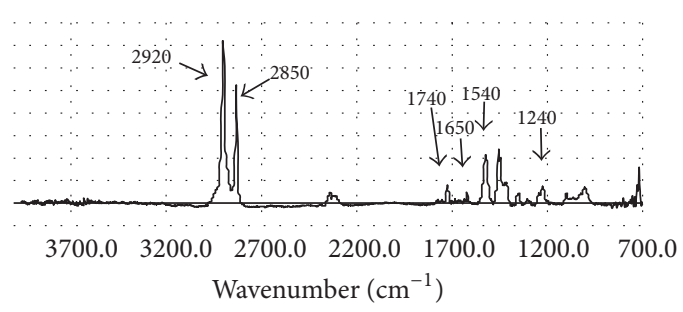

(b)

FIGURE 3: IR spectra of the five-layer film, virgin (a), aged for 8 hours by sand wind at $40^{\circ} \mathrm{C}$ (d), aged for 1000 hours at $40^{\circ} \mathrm{C}$ (b), and aged for $1000 \mathrm{~h}$ by UVA at $40^{\circ} \mathrm{C}$ (c).

is observed that all peaks of Figure 3(a) are present while, in addition, new peaks appear between $650 \mathrm{~cm}^{-1}$ and $1750 \mathrm{~cm}^{-1}$, similar as in Figures 3(b) and 3(d). The intensity of the peaks increased significantly compared to the samples kept at $40^{\circ} \mathrm{C}$. It is noticed that the peak observed in Figures 3(b) and 3(d) at $1740 \mathrm{~cm}^{-1}$ for the samples kept at $40^{\circ} \mathrm{C}$ for $8 \mathrm{hrs}$ and $1000 \mathrm{hrs}$ were not seen here.

After exposing the film to sand wind for $8 \mathrm{hrs}$, the same bands of absorptions of ageing in temperature appear, in addition to more two bands at $875 \mathrm{~cm}^{-1}$ and $1110 \mathrm{~cm}^{-1}$ (Figure 3(d)) which corresponds to the vibration of Si groups. More details are presented by Adam et al. [31] and Djakhdane et al. $[30,35]$. A peak at $1740 \mathrm{~cm}^{-1}$ has been also noticed (Figures 3(b) and 3(d)) which corresponds to the formation of ester groups for samples exposed to sand wind at $40^{\circ} \mathrm{C}$ for $8 \mathrm{hrs}$ of sand wind and for $1000 \mathrm{hrs}$. Thus, the various bands of absorption observed after the different ageing conditions show that the surface of film suffered some chemical modifications such as cross-linking, unsaturation, and oxidation. Moreover, the chemical modifications observed for the samples exposed for 8 hours to sand wind and $1000 \mathrm{hrs}$ at $40^{\circ} \mathrm{C}$ (i.e., case (b), as in Section 2.1) are almost similar. A comparison of the FTIR peaks of trilayer $[16,30]$ with that of five-layer shows that both of them have similar peaks, but the intensity of peak is more for the trilayer film. This is due to the structure of the five-layer film and its additives, which are effective in resisting the sand wind deteriorative impact.

The variation of peak at $1715 \mathrm{~cm}^{-1}$, which represents the bands of vibration of the carbonyl groups, and the peak at $1550 \mathrm{~cm}^{-1}$ and $1415 \mathrm{~cm}^{-1}$, which corresponds to the presence of $\mathrm{CH}_{2}-\mathrm{O}$ and/or $\mathrm{C}=\mathrm{C}$ functions, are due to the breaking and branching of double bonds of the polymeric material under different ageing conditions. Under the action of the radiation and/or heat, the formation of radicals occurs on the film surface, which leads to the reactions of reticulation of chains, reactions with oxygen in air, and reactions of scission of chains $[40,41]$.

The peak at $1740 \mathrm{~cm}^{-1}$ found for the samples kept at $40^{\circ} \mathrm{C}$ for $8 \mathrm{hrs}$ and 1000 hours (i.e., case (b), as in Section 2.1), which diminished for samples exposed to UVA (i.e., case (c), as in Section 2.1), indicates that the degradation mechanism is different for the UVA/temperature from that unexposed film to UVA.

3.3. Mechanical Behaviour Characterization. Figure 4 presents the mechanical stress-strain curves of the five-layer and trilayer films, virgin (i.e., case (a), as in Section 2.1) and after exposition to sand wind for $8 \mathrm{hrs}$ at $40^{\circ} \mathrm{C}$ (i.e., case (d), as in Section 2.1).

The polyethylene is considered as a ductile polymer. We can see that the stress at failure of the aged film is lower if compared to virgin film. This phenomenon can be attributed to the cross-linking, a chemical reaction induced by temperature and effect of sand wind leading to the formation of covalent bridges between the nearby segments of a polymer chain. Considering the mechanical properties, this process usually leads to an increase of the Young modulus [42] in the elastic phase. From this, we can deduce that there was an effective cross-linking after exposure to sand wind at $40^{\circ} \mathrm{C}$.

For comparison the values of the elastic modulus and percent elongation of the mono-, tri- [27, 29, 31], and five-layer films before and after the sand wind treatment are shown in Table 1. After the sand wind treatment a slight increase in the elastic modulus and a decrease in the elongation at break are observed. With regard to the monolayer film, the multilayer films have higher elastic modulus certainly due to the presence of PVAc as central layer. The elongation at break is higher for the five-layer than for the three-layer and monolayer films. The five-layer material is thus more flexible than the three-layer and monolayer films, even after exposure to a sand wind. 


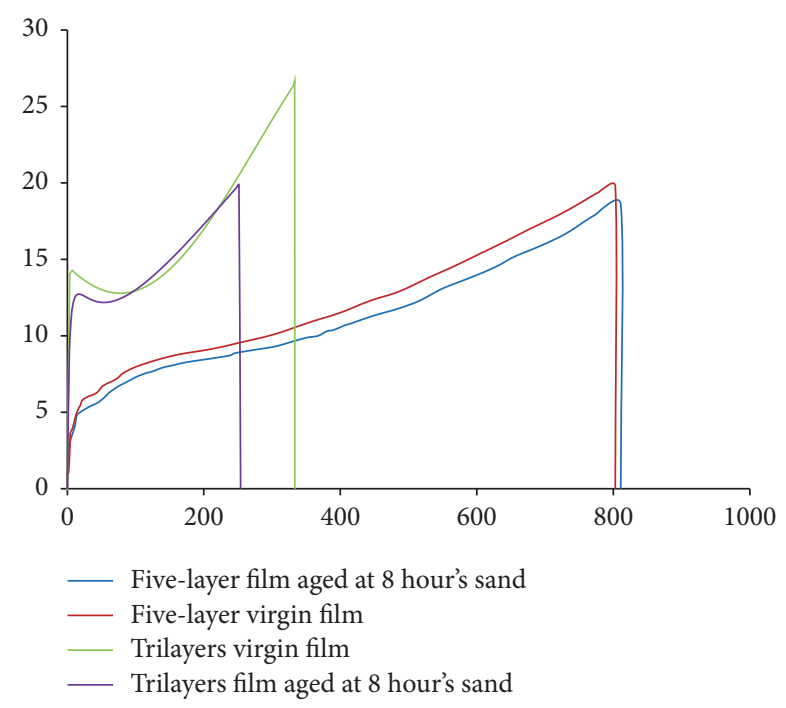

FIGURE 4: Stress-strain curves of virgin and aged (for 8 hours by sand wind at $40^{\circ} \mathrm{C}$ ) five-layer and trilayer films ( $x$-axis: strain in [\%]; $y$ axis: stress in $[\mathrm{MPa}])$.

TABLE 1: Elastic modulus and elongation at break for virgin and aged mono-, tri-, and five-layer.

\begin{tabular}{lccccc}
\hline $\begin{array}{l}\text { Type of } \\
\text { film }\end{array}$ & $\begin{array}{c}\text { Five- } \\
\text { layer } \\
\text { initial }\end{array}$ & $\begin{array}{c}\text { Five- } \\
\text { layer } \\
\text { sand- } \\
\text { wind }\end{array}$ & $\begin{array}{c}\text { Trilayer } \\
\text { initial }\end{array}$ & $\begin{array}{c}\text { Trilayer } \\
\text { sand- } \\
\text { wind }\end{array}$ & $\begin{array}{c}\text { Monolayer } \\
\text { initial }\end{array}$ \\
\hline $\begin{array}{l}\text { Elastic } \\
\text { modulus } \\
\text { (MPa) }\end{array}$ & 0.64 & 0.78 & 0.77 & 0.88 & 0.31 \\
$\begin{array}{l}\text { Elongation } \\
\text { at break } \\
(\%)\end{array}$ & 840 & 820 & 420 & 410 & 260 \\
\hline
\end{tabular}

\section{Conclusions}

The effect of ageing under three different conditions on five-layer LDPE greenhouse covering film has been studied by using several physic-chemical characterization methods. Optical images show distinctly that the deterioration on the surface of the trilayers is more severe when compared to five-layer film and the deteriorative effects grow with time of exposure. The FTIR spectra and free surface energy calculated using contact angle method indicated that all the three test conditions modified the film surface due to crosslinking, oxidation, and chain scission reactions. In FTIR a band vibration of Si groups appeared after exposure to sand wind. The mechanical tests showed a slight increase in the elastic modulus and a decrease in the elongation at break after ageing. This is attributed to the chains cross-linking. Due to the deterioration of the superficial layers of the material, the gas permeability flow increased slightly through the aged films. It can be concluded that the surface properties of the films were more affected by the ageing conditions, and the properties of the five-layer film are much better when compared to mono- or trilayer films after exposure.
Since the formulation of a plastic film for greenhouse covering is currently based on chemical considerations about the composition of the polymer and its additives, whereas the technical aspects about the performance of this material during its working life are usually poorly or totally not considered during their design and engineering phase, further experimental analysis should be conducted. The limited life of agricultural plastic films, even if they are produced with considerable quantities of appropriate additives, would indeed be enhanced thanks to new more efficient customized formulations, performed also with the support of suitable equations able to predict their useful lifetime on the basis of the main meteorological characteristics of the area where this material will be exposed and the operative conditions (contact with pesticides/agrochemicals, external pollution, contact with structural frames, etc.).

\section{Competing Interests}

The authors declare that they have no competing interests.

\section{References}

[1] P. Picuno, "Innovative material and improved technical design for a sustainable exploitation of agricultural plastic film," Polymer-Plastics Technology and Engineering, vol. 53, no. 10, pp. 1000-1011, 2014.

[2] A. Dimitrijevic, D. Statuto, and C. Sica, "Possibilities of using spatial analysis (GIS) as an input data tool for the greenhouse decision support model," in Proceedings of the 43rd Symposium on Actual Tasks on Agricultural Engineering (ATAE '15), vol. 43, pp. 451-459, Opatija, Croatia, February 2015.

[3] D. Statuto, G. Cillis, and P. Picuno, "Analysis of the effects of agricultural land use change on rural environment and landscape through historical cartography and GIS tools," Journal of Agricultural Engineering, vol. 47, no. 1, pp. 28-39, 2016.

[4] E. Espí, A. Salmerón, A. Fontecha, Y. García, and A. I. Real, "Plastic films for agricultural applications," Journal of Plastic Film and Sheeting, vol. 22, no. 2, pp. 85-102, 2006.

[5] D. Statuto, A. Tortora, and P. Picuno, "A GIS approach for the quantification of forest and agricultural biomass in the Basilicata region," Journal of Agricultural Engineering, vol. 44, no. 1, pp. 627-631, 2013.

[6] D. Statuto, G. Cillis, and P. Picuno, "Historical cartography and GIS tools for the analysis of land use and landscape changes," in Proceedings of the 43rd Symposium on Actual Tasks on Agricultural Engineering (ATAE '15), vol. 43, pp. 441-450, Opatija, Croatia, February 2015.

[7] D. Briassoulis and E. Schettini, "Analysis and design of lowdensity polyethylene greenhouse films," Biosystems Engineering, vol. 84, no. 3, pp. 303-314, 2003.

[8] D. Briassoulis, "Mechanical behaviour of biodegradable agricultural films under real field conditions," Polymer Degradation and Stability, vol. 91, no. 6, pp. 1256-1272, 2006.

[9] A. Hanafi and A. Papasolomontos, "Integrated production and protection under protected cultivation in the Mediterranean region," Biotechnology Advances, vol. 17, no. 2-3, pp. 183-203, 1999.

[10] A. Dehbi, A.-H. I. Mourad, K. Djakhdane, and A. Hilal-Alnaqbi, "Degradation of thermomechanical performance and lifetime 
estimation of multilayer greenhouse polyethylene films under simulated climatic conditions," Polymer Engineering \& Science, vol. 55, no. 2, pp. 287-298, 2015.

[11] P. A. Dilara and D. Briassoulis, "Degradation and stabilization of low-density polyethylene films used as greenhouse covering materials," Journal of Agricultural Engineering Research, vol. 76, no. 4, pp. 309-321, 2000.

[12] D. Briassoulis, "Analysis of the mechanical and degradation performances of optimised agricultural biodegradable films," Polymer Degradation and Stability, vol. 92, no. 6, pp. 1115-1132, 2007.

[13] E. Schettini and G. Vox, "Effects of agrochemicals on the radiometric properties of different anti-UV stabilized EVA plastic films," Acta Horticulturae, vol. 956, pp. 515-522, 2012.

[14] J. Sampers, "Importance of weathering factors other than UV radiation and temperature in outdoor exposure," Polymer Degradation and Stability, vol. 76, no. 3, pp. 455-465, 2002.

[15] A. Dehbi and A.-H. I. Mourad, "Durability of mono-layer versus tri-layers LDPE films used as greenhouse cover: comparative study," Arabian Journal of Chemistry, vol. 9, supplement 1, pp. S282-S289, 2016.

[16] A.-H. I. Mourad and A. Dehbi, "On use of trilayer low density polyethylene greenhouse cover as substitute for monolayer cover," Plastics, Rubber and Composites: Macromolecular Engineering, vol. 43, no. 4, pp. 111-121, 2014.

[17] E. Schettini, F. R. De Salvador, G. Scarascia-Mugnozza, and G. Vox, "Radiometric properties of photoselective and photoluminescent greenhouse plastic films and their effects on peach and cherry tree growth," Journal of Horticultural Science \& Biotechnology, vol. 86, no. 1, pp. 79-83, 2011.

[18] P. Picuno, C. Sica, R. Laviano, A. Dimitrijević, and G. ScarasciaMugnozza, "Experimental tests and technical characteristics of regenerated films from agricultural plastics," Polymer Degradation and Stability, vol. 97, no. 9, pp. 1654-1661, 2012.

[19] L. Stefani, M. Zanon, M. Modesti, E. Ugel, G. Vox, and E. Schettini, "Reduction of the environmental impact of plastic films for greenhouse covering by using fluoropolymeric materials," Acta Horticulturae, vol. 801, pp. 131-137, 2008.

[20] F. R. De Salvador, G. Scarascia Mugnozza, G. Vox, E. Schettini, M. Mastrorilli, and M. Bou Jaoudé, "Innovative photoselective and photoluminescent plastic films for protected cultivation," Acta Horticulturae, vol. 801, pp. 115-121, 2008.

[21] A. Dehbi, A.-H. I. Mourad, and A. Bouaza, "Ageing effect on the properties of tri-layer polyethylene film used as greenhouse roof," Procedia Engineering, vol. 10, pp. 466-471, 2011.

[22] A. Dehbi, A.-H. I. Mourad, and A. Bouaza, "Degradation assessment of LDPE multilayer films used as a greenhouse cover: natural and artificial aging impacts," Journal of Applied Polymer Science, vol. 124, no. 4, pp. 2702-2716, 2012.

[23] E. Schettini, L. Stefani, and G. Vox, "Interaction between agrochemical contaminants and UV stabilizers for greenhouse EVA plastic films," Applied Engineering in Agriculture, vol. 30, no. 2, pp. 229-239, 2014.

[24] A. C. Tavares, J. V. Gulmine, C. M. Lepienski, and L. Akcelrud, "The effect of accelerated aging on the surface mechanical properties of polyethylene," Polymer Degradation and Stability, vol. 81, no. 2, pp. 367-373, 2003.

[25] D. Briassoulis and A. Aristopoulou, "Adaptation and harmonisation of standard testing methods for mechanical properties of low-density polyethylene (LDPE) films," Polymer Testing, vol. 20, no. 6, pp. 615-634, 2001.
[26] G. Scarascia-Mugnozza, E. Schettini, R. V. Loisi, I. Blanco, and G. Vox, "Georeferencing of agricultural plastic waste," Rivista di Studi sulla Sostenibilità, vol. 1, pp. 71-82, 2016.

[27] D. Briassoulis, E. Babou, M. Hiskakis et al., "Review, mapping and analysis of the agricultural plastic waste generation and consolidation in Europe," Waste Management and Research, vol. 31, no. 12, pp. 1262-1278, 2013.

[28] K. Guenachi, A. Hamou, N. Hassini, J.-M. Saiter, S. Marais, and E. Beucher, "Influence of sandwinds on the durability of polyethylene greenhouse aged under sub-saharan climatic conditions," Materials Research Innovations, vol. 6, no. 4, pp. 174-178, 2002.

[29] B. Youssef, M. Benzohra, J. M. Saiter, A. Dehbi, and A. Hamou, "Ageing characterization to determine the life duration of different LDPE based devices used for greenhouse roof," in Proceedings of the International Symposium on High Technology for Greenhouse System Management: Greensys, vol. 801, pp. 123130, 2007.

[30] K. Djakhdane, A. Dehbi, A.-H. I. Mourad, A. Zaoui, and P. Picuno, "The effect of sand wind, temperature and exposure time on tri-layer polyethylene film used as greenhouse roof," Plastics, Rubber and Composites, vol. 45, no. 8, pp. 346-351, 2016.

[31] A. Adam, S. A. Kouider, B. Youssef, A. Hamou, and J. M. Saiter, "Studies of polyethylene multi layer films used as greenhouse covers under Saharan climatic conditions," Polymer Testing, vol. 24, no. 7, pp. 834-838, 2005.

[32] P. A. Dilara and D. Briassoulis, "Standard testing methods for mechanical properties and degradation of low density polyethylene (LDPE) films used as greenhouse covering materials: a critical evaluation," Polymer Testing, vol. 17, no. 8, pp. 549-585, 1998.

[33] A.-H. I. Mourad, "Thermo-mechanical characteristics of thermally aged polyethylene/polypropylene blends," Materials and Design, vol. 31, no. 2, pp. 918-929, 2010.

[34] B. Youssef, A. E. Dehbi, A. Hamou, and J. M. Saiter, "Natural ageing of tri-layer polyethylene film: evolution of properties and lifetime in north Africa region," Materials \& Design, vol. 29, no. 10, pp. 2017-2022, 2008.

[35] A. Dehbi, K. Djakhdane, and A.-H. I. Mourad, "Impact of Degradation of Polyethylene Films under Simulated Climatic Conditions on their mechanical behavior and thermal stability and lifetime," American Society of Mechanical Engineers. Pressure Vessels and Piping Division, Parts A and B, vol. 6, pp. 131$135,2012$.

[36] AFNOR, "Matières plastiques-feuilles-présentation et dimensions-méthodes de contrôle (Plastic sheet. Presentation and dimensions. Methods of control)," AFNOR NF T54-101, AFNOR-Norme Française, Paris, France, 1974.

[37] F. Carrasco, P. Pagès, S. Pascual, and X. Colom, "Artificial aging of high-density polyethylene by ultraviolet irradiation," European Polymer Journal, vol. 37, no. 7, pp. 1457-1464, 2001.

[38] P. Gijsman and J. Sampers, "The influence of oxygen pressure and temperature on the UV-degradation chemistry of polyethylene," Polymer Degradation and Stability, vol. 58, no. 1-2, pp. 5559, 1997.

[39] N. S. Allen, M. Edge, D. Holdsworth et al., "Ageing and spectroscopic properties of polyethylenes: comparison with metallocene polymer," Polymer Degradation and Stability, vol. 67, no. 1, pp. 57-67, 2000.

[40] L. Küpper, J. V. Gulmine, P. R. Janissek, and H. M. Heise, "Attenuated total reflection infrared spectroscopy for micro-domain 
analysis of polyethylene samples after accelerated ageing within weathering chambers," Vibrational Spectroscopy, vol. 34, no. 1, pp. 63-72, 2004.

[41] J. V. Gulmine, P. R. Janissek, H. M. Heise, and L. Akcelrud, "Degradation profile of polyethylene after artificial accelerated weathering," Polymer Degradation and Stability, vol. 79, no. 3, pp. 385-397, 2003.

[42] C. Sica and P. Picuno, "Spectro-radiometrical characterization of plastic nets for protected cultivation," Acta Horticulturae, vol. 801, pp. 245-252, 2008. 

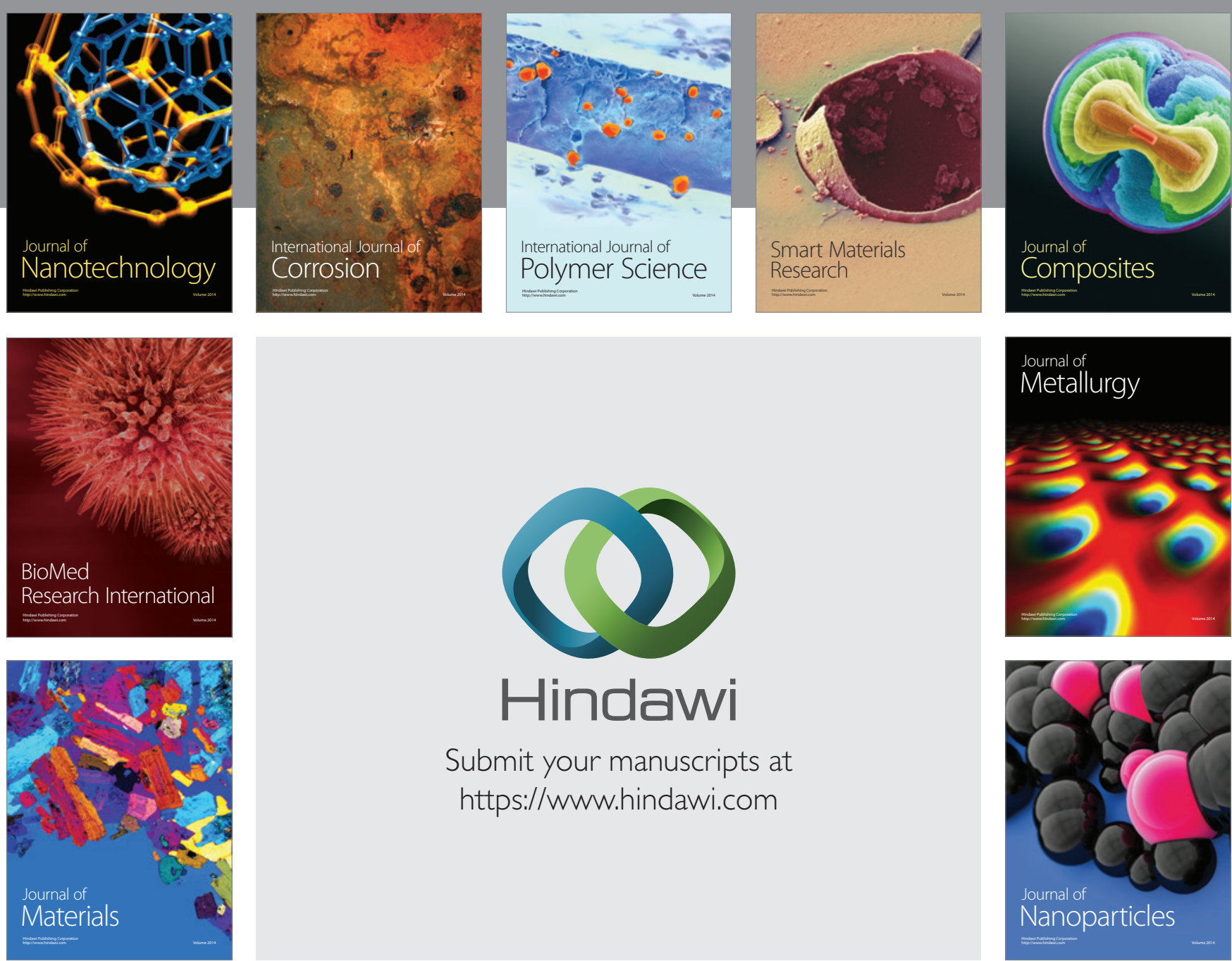

\section{Hindawi}

Submit your manuscripts at

https://www.hindawi.com

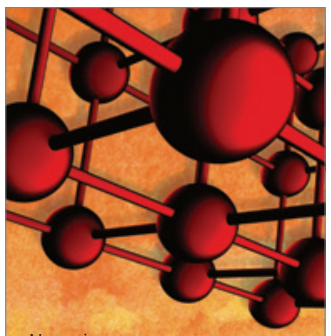

Materials Science and Engineering
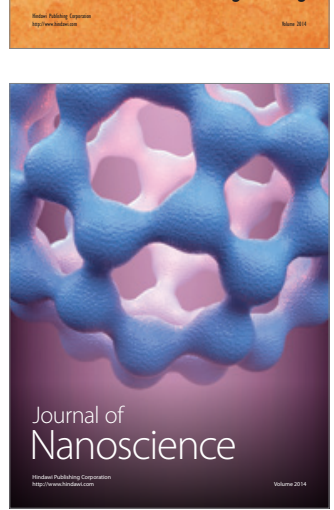
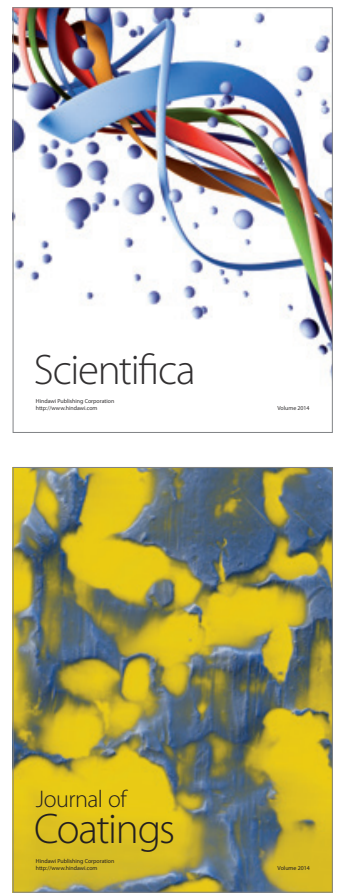
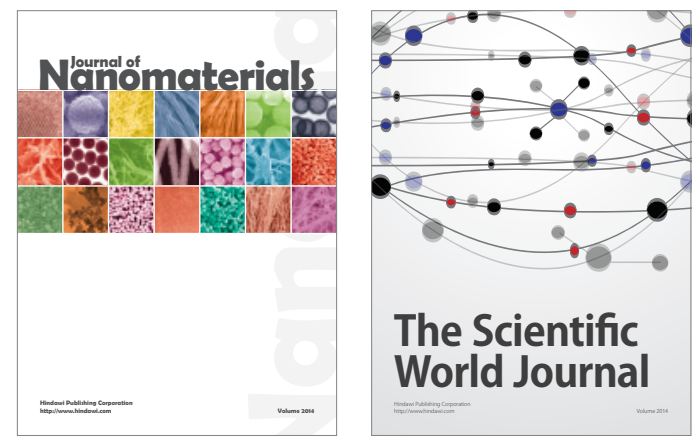

The Scientific World Journal
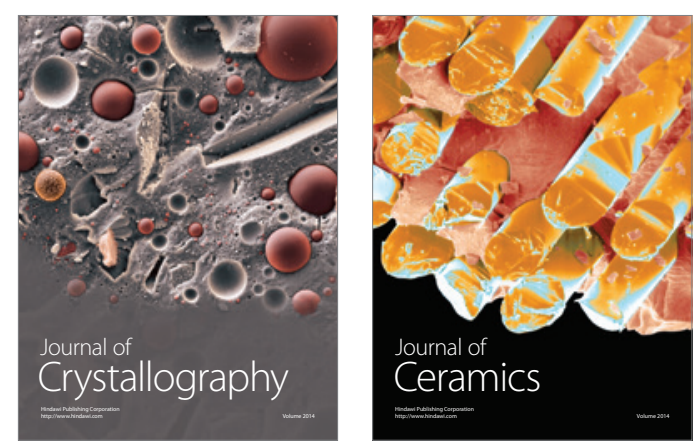
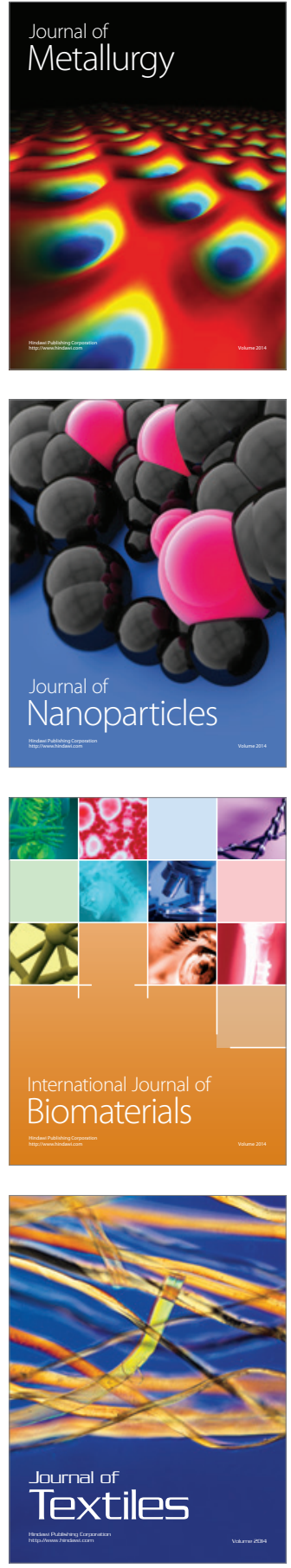